\title{
Substituent effects on the mutagenicity of phenyl glycidyl ethers in Salmonella typhimurium
}

\author{
Steven H. Neau, Barry H. Hooberman, Stephen W. Frantz \\ and J.E. Sinsheimer* \\ College of Pharmacy, The University of Michigan, Ann Arbor, MI 48109 (U.S.A.) \\ (Received 27 March 1981) \\ (Revision received 17 September 1981) \\ (Accepted 21 October 1981)
}

\section{Summary}

Phenyl glycidyl ether and 6 para-substituted derivatives, the methoxy, tert-butyl, methyl, chloro, bromo and nitro compounds, were tested in the Ames' test for mutagenicity. With the exception of the tert-butyl derivative in TA1535, all 7 compounds were mutagenic in both strains TA100 and TA1535. Electron-donating groups in the para position decreased mutagenicity while electron-withdrawing groups increased this mutagenicity. The mutagenicity of the series of compounds in both strains could be correlated to the Hammett substituent constants for the para-substituent groups. The glycidyl ether results might best be considered in terms of a normal reaction with bionucleophiles as compared to the literature report for the correlation of mutagenicity with abnormal product formation for a styrene oxide series.

Glycidyl ethers of the general formula $\mathrm{R}-\mathrm{OCH}_{2}-\mathrm{CH}-\mathrm{CH}_{2}$ are readily available laboratory and industrial chemicals. They are widely used as alkylating agents, especially as reactive diluents with epoxide resins (Potter, 1970). The extent of human exposure as well as the biological effects of glycidyl ethers have recently been reviewed (NIOSH, 1978; Stein et al., 1979). These reviews do not report human carcinogenic or mutagenic effects, but recommendations are made for epidemiologic and carcinogenic studies. These recommendations are based upon the results of bacterial as well as animal studies and limits were established for occupational exposure to several epoxides.

The bacterial studies include literature reports of the mutagenicity for selected

* To whom correspondence should be addressed. 


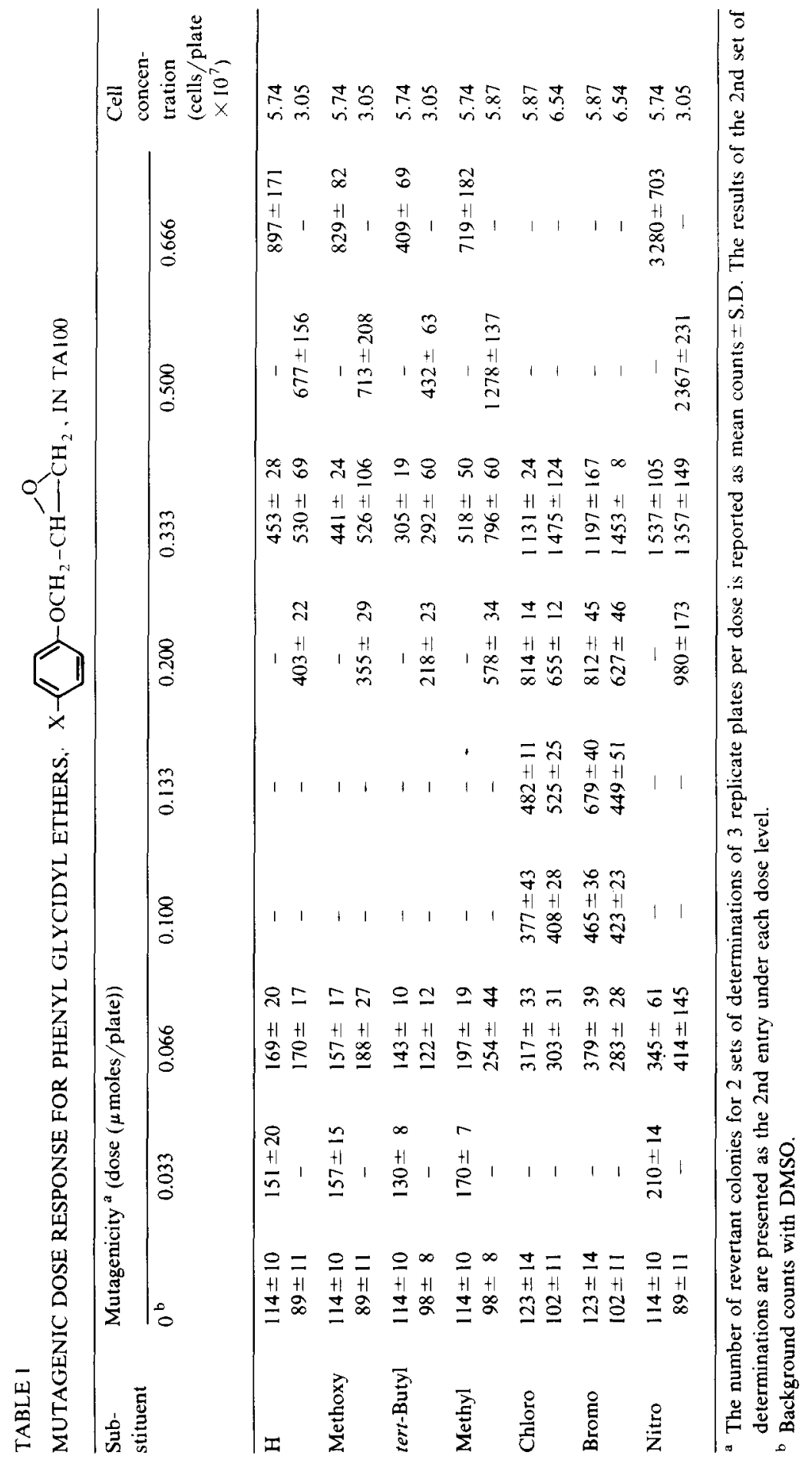


glycidyl ethers (NIOSH, 1978; Greene et al., 1979; Ivie et al., 1980) as well as the parent alcohol, glycidol (Green et al., 1979) with Salmonella typhimurium strains TA 100 and TA1535 in the Ames procedure (Ames et al., 1975).

There are indications in the literature that the polarity of substituent groups in a homologous series of compounds influences mutagenicity. For example, in a previous study (Wade et al., 1978) we reported that electron-withdrawing substituents in the propyelene oxide series appeared to increase mutagenicity. More recently, Sugiura and Goto (1981) have shown with a series of styrene oxide derivatives that electron-withdrawing groups at the para or meta positions decreased mutagenicity with Hammett reaction constant correlating its attack on the benzylic carbon.

A quantitative mutagenicity-structure comparison of a series of phenyl glycidyl ethers is of interest because of their commercial significance and because they represent the more mutagenic examples of mono-substituted aliphatic epoxides. It is the purpose of the present investigation to establish the relative mutagenicity in the Ames procedure of a homologous series of 7 phenyl glycidyl ethers and to determine the effect of electron-withdrawing and donating groups at the para phenyl position of these epoxides upon mutagenicity.

\section{Materials and methods}

\section{Chemicals}

Glycidyl phenyl ether, $p$-bromophenyl 2,3-epoxypropyl ether, 2,3-epoxypropyl $p$-methoxyphenyl ether, $p$-chlorophenyl 2,3-epoxypropyl ether, and p-tert-butylphenyl 2,3-epoxypropyl ether were obtained from Aldrich Chemical Company, Inc. (Milwaukee, WI). 2,3-Epoxypropyl $p$-tolyl ether was from ICN Life Sciences Group (Plainview, NY) while 1,2-epoxy-3-( $p$-nitrophenoxy)-propane was from Eastman Kodak Company (Rochester, NY).

All of these chemicals, except the nitro compound, showed a single spot for thin-layer chromatography on silica with either toluene or a $2 \%$ methanol-methylene chloride system. To satisfy this test for purity, the nitro epoxide required purification by HPLC over silica with methylene chloride as solvent.

\section{Culture preparation}

Minimal agar with Vogel-Bonner Medium E and top agar were prepared by the method described by Ames et al. (1975) using sterile petri dishes ('Muta-Assay', Falcon, Oxnard, CA).

Salmonella typhimurium TA 100 and TA 1535 were obtained from Dr. Bruce Ames (University of California, Berkeley, CA). Preparation of the stock cultures was by the Ames method. Nutrient broth, inoculated with one of the 2 tester strains, was allowed to sit overnight. It was then brought to $37^{\circ} \mathrm{C}$ in a constant-temperature water bath, and shaken until it reached an absorbance at $560 \mathrm{~nm}$ of $0.75-0.82$. The plate-incorporation technique was used as described by Ames et al. (1975). Solutions of the test compounds in DMSO were freshly prepared on the day of the test and added as $0.1-\mathrm{ml}$ aliquots per plate. 


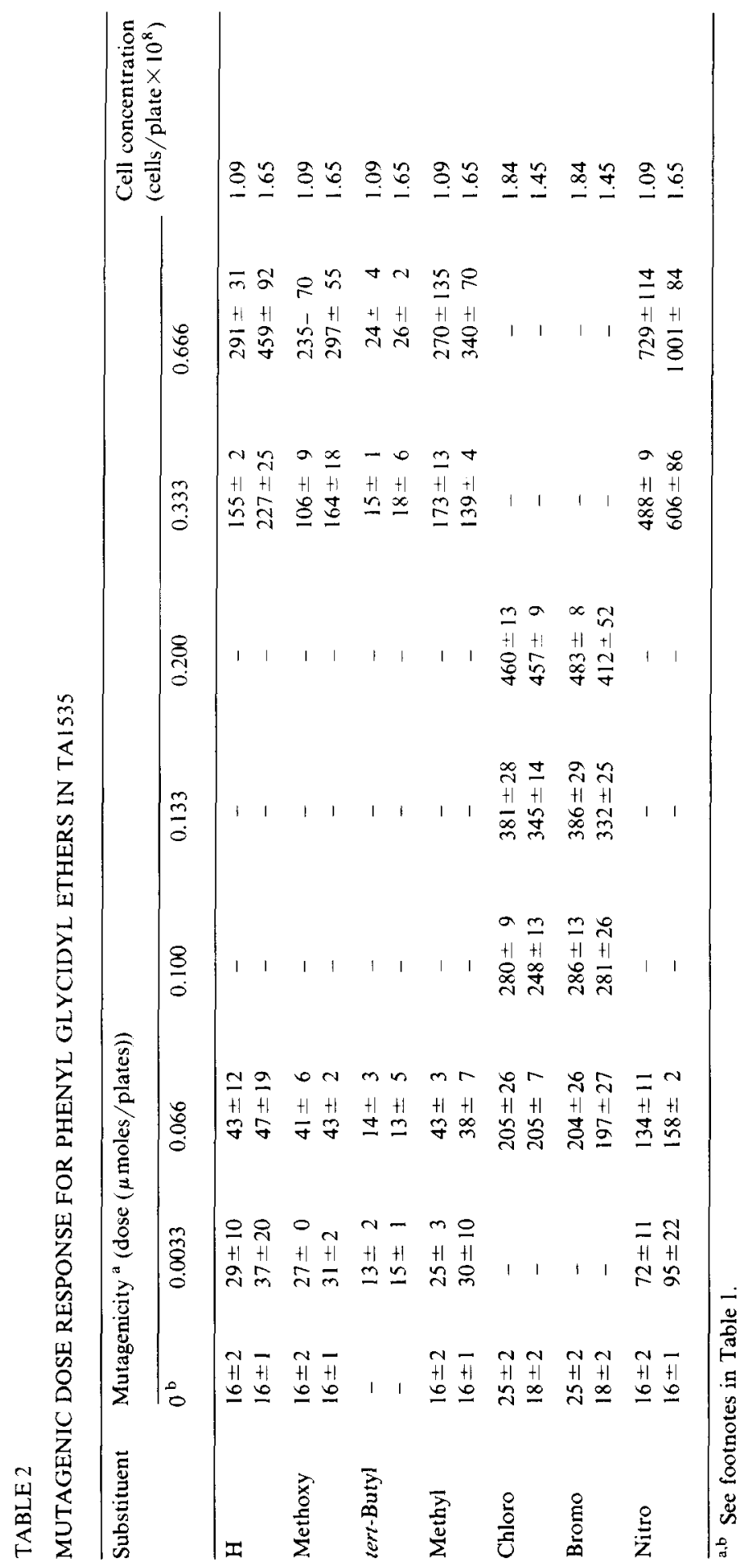




\section{Results}

The number of revertants per plate as a function of concentration was examined with TA100 and TA1535 to determine whether a linear dose-response range could be established for each compound. The indicated presence of such a linear response was reconfirmed on a second day over the same or more suitable dose range. The results of these tests are summarized in Tables 1 and 2.

Initial tests with both the chloro and bromo compounds showed a dramatic decrease in countable revertants for doses above $0.333 \mu$ moles per plate. We interpreted these results in agreement with that reported by El-Tantawy and Hammock (1980) for the chloro compound as being an indication of toxicity. However, toxicity was not established when $10^{-5}$ dilutions of either TA100 or TA1535 were grown in histidine-supplemented media in the presence of the apparently toxic concentration of either compound. Subsequent testing at these concentrations in the normal Ames procedure with histidine-limited plates revealed that when these plates were incubated for an additional $12-24 \mathrm{~h}$, the number of revertants increased to levels predictable from the lower portion of their dose-response curves. Thus, what we originally considered to be cell toxicity was, in fact, an

\section{TABLE 3}

AVERAGE MUTAGENICITY AT $0.1 \mu$ moles PER PLATE FOR THE GLYCIDYL ETHERS

\begin{tabular}{|c|c|c|c|}
\hline \multirow[t]{2}{*}{ Substituent } & \multicolumn{2}{|c|}{ Revertants/plate ${ }^{\text {a }}$} & \multirow{2}{*}{$\begin{array}{l}\text { Hammett } \\
\text { values } \\
\sigma\end{array}$} \\
\hline & $\operatorname{TA} 100(N)$ & TA1535 $(N)$ & \\
\hline $\mathrm{H}$ & $\begin{array}{l}241 \pm 25(6) \\
217 \pm 15(4)\end{array}$ & $\begin{array}{l}149 \pm 26(5) \\
105 \pm 13(4)\end{array}$ & 0.000 \\
\hline Methoxy & $\begin{array}{l}199 \pm 14(4) \\
180 \pm 34(6)\end{array}$ & $\begin{array}{l}105 \pm 30(5) \\
110 \pm 31(5)\end{array}$ & -0.268 \\
\hline tert-Butyl & $\begin{array}{l}191 \pm 22(4) \\
134 \pm 16(5)\end{array}$ & $\begin{array}{l}20 \pm 3(6) \\
21 \pm 16(6)\end{array}$ & -0.197 \\
\hline Methyl & $\begin{array}{l}276 \pm 28(4) \\
241 \pm 23(6)\end{array}$ & $\begin{array}{l}122 \pm 26 \\
127 \pm 21(6)\end{array}$ & -0.170 \\
\hline Chloro & $\begin{array}{l}370 \pm 36(5) \\
263 \pm 67(3)\end{array}$ & $\begin{array}{l}194 \pm 20(5) \\
214 \pm 59(5)\end{array}$ & 0.227 \\
\hline Bromo & $\begin{array}{l}299 \pm 34(6) \\
254 \pm 85(3)\end{array}$ & $\begin{array}{l}248 \pm 29(5) \\
253 \pm 71(6)\end{array}$ & 0.232 \\
\hline Nitro & $\begin{array}{l}407 \pm 73(6) \\
482 \pm 133(5)\end{array}$ & $\begin{array}{l}464 \pm 56 \\
469 \pm 35(5)\end{array}$ & 0.778 \\
\hline Background & $\begin{array}{r}99 \pm 24(3) \\
105 \pm 16(3)\end{array}$ & $\begin{array}{r}13 \pm 5(3) \\
9 \pm 2(3)\end{array}$ & \\
\hline $\begin{array}{l}\text { Cell concentration } \\
\left(\text { cells } / \text { plate } \times 10^{7}\right)\end{array}$ & $\begin{array}{l}7.96 \\
4.51\end{array}$ & $\begin{array}{l}8.41 \\
6.96\end{array}$ & \\
\hline
\end{tabular}

a See footnote in Table 1. 
inhibition of growth. de Serres and Shelby (1979) noted a similar effect in the Ames test in their discussion of incubation times.

While dose-response relationships could be established and confirmed for all the epoxides with the exception of the tert-butyl compound in TA1535, there is considerable day-to-day variation in the results reported in Tables 1 and 2. Day-to-day variation in the Ames test, even under controlled conditions, has been reported by Cheli et al. (1980) as well as by Peak et al. (1980). Recently Salmeen and Dursin

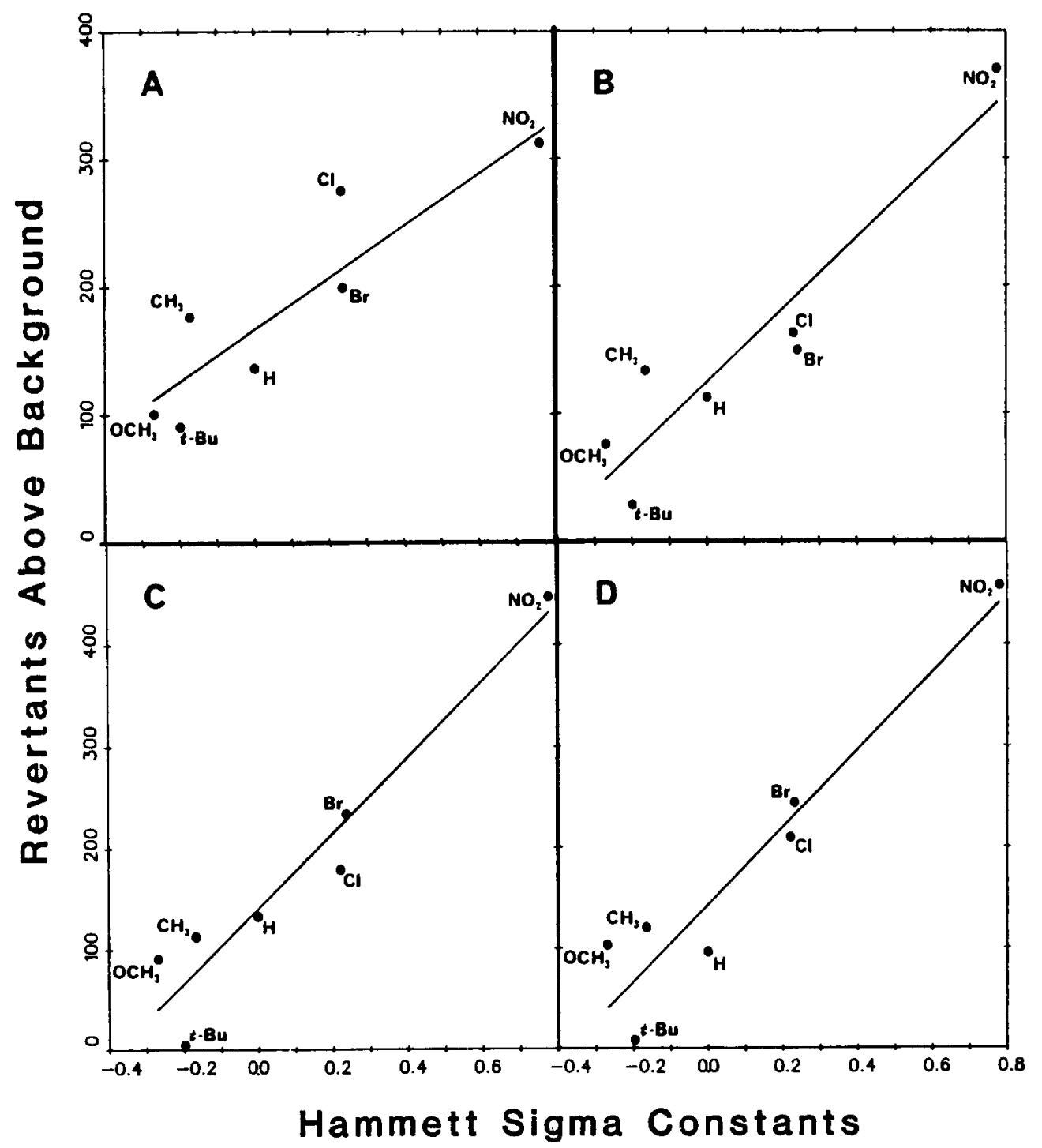

Fig. 1. Correlations of the mutagenicity (revertants above background) for the phenyl glycidyl ether series with Hammett reactivity constants for the para substituents. (A) Determination 1 with TAl00; (B) determination 2 with TA100; (C) determination 1 with TA1535; (D) determination 2 with TA1535. 
(1981) noted that factors affecting the growth rate of bacteria among experiments must be brought under practical control to obtain reproducibility.

Our approach for such practical control is to run all comparisons of a series of compounds as multiple samples at the same dose, at the same time, under the same conditions and from the same initial inoculum. The results obtained in this manner were then confirmed in a second experiment. The dose used based upon the results in Tables 1 and 2 was $0.100 \mu$ moles/plate. This dose was clearly in the linear portion of the dose-response curve for all compounds (except for the $t$-butyl derivative in TA1535) and was indicated to give a reasonable response above background but was well below the growth-inhibiting level for the chloro and bromo compounds.

Results for these tests are given in Table 3 together with the Hammett $\sigma$ values of the substituents and are shown in Fig. 1. The linear least square lines for TA100 (Fig. 1A) are $y=202 X+167(r=0.8982)$ and (Fig. 1B) $y=282 X+124(r=0.9319)$ for the repeated test of the 7 compounds. For TA1535 these correlation lines are (Fig. 1C) $y=373 X+141(r=0.9589)$ and (Fig. 1D) $y=382 X+144(r=0.9533)$ for the second test of 7 compounds.

\section{Discussion}

In an approach that is consistent with structure-biological activity relationship studies (Seydel, 1971) for aromatic compounds involving electronic effects of substituent groups, the Hammett $\sigma$ constants reported for the ionization of benzoic acid (McDaniel and Brown, 1958) were compared to the mutagenicity of the phenyl glycidyl ethers. As noted in Fig. 1 and from the correlation coefficients, there is a reasonable correlation of the mutagenicity in both TA100 and TA1535 of phenyl glycidyl ethers as compared to the Hammett $\sigma$ values for the para substituents. There is a general increase in mutagenicity with an increase in the strength of the electron-withdrawing substituent. The increase in mutagenicity is particularly pronounced for the bromo, chloro and nitro groups. Electron-withdrawing groups increase the positive charge on the carbon atom of the epoxide ring and the presence of such groups have been shown to facilitate the reaction of epoxides with nucleophiles (Chapman et al., 1959). Although the substituted aromatic compounds included in this study are separated from the epoxide carbon by both the ether oxygen and a methylene group, the Hammett o substituent constants still correlate with mutagenicity. Reines et al. (1970) in a study of the rates of reaction of 2 series of glycidyl ethers with dibutylamine suggest that the ether oxygen actually enhances the reaction by its ability, initially, to hydrogen bond with the nucleophile. They postulate that such association places the nucleophile in a favorable position for attacking the epoxide moiety. Their proposed intermediate

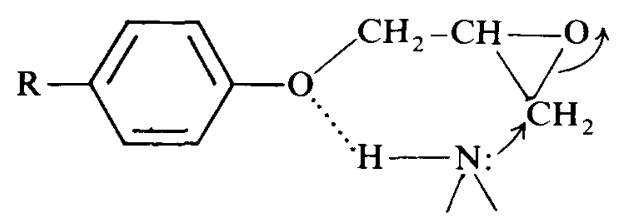


results in attack on the terminal, least substituted carbon of the epoxide. If a similar normal product (Chapman et al., 1959) is formed with bionucleophiles, this would be in contrast to abnormal product formation at the benzylic sites of styrene oxide derivatives i.e., the more substituted epoxide carbon (Sugiura and Goto, 1981). This would be consistent with the reverse order of Hammett $\sigma$ correlations in the glycidyl ether series as compared to the styrene oxide derivatives.

\section{Acknowledgment}

The authors express their appreciation to Dr. Bruce Ames, University of California at Berkeley, for supplying the Salmonella strains.

This investigation was suppported in part by Grant No. 1 R01 CA25770 awarded by the National Cancer Institute, DHHS.

\section{References}

Ames, B.M., J. McCann and E. Yamasaki (1975) Methods for detecting carcinogens and mutagens with the Salmonella/mammalian-microsome mutagenicity test, Mutation Res., 31, 347-364.

Chapman, N.B., N.S. Isaacs and R.E. Parker (1959) The mechanism of epoxide reactions, J. Chem. Soc., 1925.

de Serres, F.J., and M.D. Shelby (1979) Recommendations on data production and analysis using the Salmonella/microsome mutagenicity assay, Mutation Res., 64, 159-165.

El-Tantawy, M.A., and B.D. Hammock (1980) The effects of hepatic microsomal and cytosolic subcellular fractions on the mutagenic compounds in the Salmonella assay, Mutation Res., 79, 59-71.

Greene, E.J., M.A. Friedman, J.A. Sherrod and A.J. Salerno (1979) In vitro mutagenicity and cell transformation screening of phenylglycidyl ether, Mutation Res., 67, 9-19.

Ivie, G.W., J.T. Macgregor and B.D. Hammock (1980) Mutagenicity of psoralen epoxides, Mutation Res., 79, 73-77.

McDaniel, D.H., and H.C. Brown (1958) An extended table of Hammett substituent constants based on the ionization of substituted benzoic acids, J. Org. Chem., 23, 420-427.

NIOSH (1978) Criteria for a recommended standard. ... Occupational exposure to glycidyl ethers, U.S. Department of Health, Education and Welfare, Public Health Service, Center for Disease Control, National Institute for Occupational Safety and Health, Cincinnati.

Potter, W.G. (1970) Epoxide Resins, Springer, New York, pp. 109-115.

Seydel, J.K. (1971) Physicochemical approaches to the rational development of new drugs, E.J. Ariëns (Ed.), Drug Design, Academic Press, New York, pp. 343-379.

Stein, H.P., N.A. Leidel and J.M. Lane (1979) NIOSH Current Intelligence Bulletin, Glycidyl ethers, Am. Ind. Hyg., 40, A36-A51.

Sugiura. K., and M. Goto (1981) Mutagenicities of styrene oxide derivatives on bacterial test systems: relationship between mutagenic potencies and chemical reactivity, Chem.-Biol. Interact., 35, 71-91.

Wade, D.R., S.C. Airy and J.E. Sinsheimer (1978) Mutagenicity of aliphatic epoxides, Mutation Res.. 58 , 217-223. 